\title{
LOS RETOS DE LA SEGURIDAD SOCIAL ESPAÑOLA EN EL SIGLO XXI: DE LAS PEN- SIONES A LA INCAPACIDAD TEMPORAL ${ }^{470}$
}

The challenges of the spanish social security in the XXI century: pensions for temporary disability

\section{José Luis Tortuero Plaza}

Catedrático de Derecho del Trabajo y de la Seguridad Social y Director del Titulo de Experto en Seguridad Social de la Universidad Complutense de Madrid. E-mail: jltortuero@gmail.com

\section{RESUMEN}

El trabajo pretende realizar un análisis de los principales retos del Sistema español de Seguridad Social, utilizando como hilo conductor dos prestaciones hegemónicas. Por un lado la jubilación, que constituye el centro neurálgico de cualquier sistema de pensiones, tanto por su importancia cuantitativa, como cualitativa. Por otro, los instrumentos de protección temporal que cubre las alteraciones de la salud con efecto incapacitante y de carácter transitorio.

Palabras Claves : Seguridad social española. Incapacidad temporal .

\begin{abstract}
This work aims to conduct an analysis of the main challenges of the Spanish Social Security System, using thread two benefits hegemonic. For one retirement, which constitutes the hub of any pension system , both by their quantitative importance, such as qualitative. Furthermore, temporary protective covering health with disabling effect alterations and instruments of a transitory nature.
\end{abstract}

Keywords Spanish Social Security system. Temporary disability.

${ }_{470}$ La presente Ponencia se inserta en las actividades del Proyecto de Investigación "La Incapacidad Temporal en el trabajo de hombres y mujeres" (Subprograma de Proyectos de Investigación Fundamental no orientada, convocatoria 2011 (DER2011-29448-C03-01). 
Sumario: I. La jubilación como centro neuralgico del sistema de pensiones.1. Demografia, sistema de pensiones y costes: una aproximación en clave europea. 2. Rreflexiones sobre la edad de jubilacion y su reforma.3. Tiempos de crisis versus tiempos de reformas. 3.1. La reforma de la jubilación en la Ley 27/2011, sobre actualización, adecuación y modernización del Sistema de la Seguridad Social: la clave del dialogo social. 3.2. La implantación del factor de sostenibilidad. 3.2.1. Antecedentes: La creación del Comité de Expertos.3.2.2. El proyecto de Ley y la Ley 23/2013, de 23 de diciembre, reguladora del Factor de Sostenibilidad y del Índice de Revalorización del Sistema de Pensiones de la Seguridad Social 3.2.3. La reforma y la ruptura del consenso político y social. II. La función de las prestaciones temporales: la incapacidad temporal. 1. El modelo de gestión y control de la incapacidad temporal: un proceso de reforma interminable. 2. Nuevas reglas de gestión y control: el real decreto 625/2014.2.1 Ubicación y alcance de la reforma. 2.2. Elementos destacables de la reforma y sus puntos críticos.2.2.1. Instrumentos de control sobre la actuación de los facultativos y centralización de la información. 2.2.2. La fragmentación temporal de los procesos como mecanismo control-presión.2.2.3. Facultades de control y la posible vulneración del derecho a la intimidad.

\section{LA JUbILACIÓN COMO CENTRO NEURALGICO DEL SISTEMA DE PENSIONES}

De todos los riesgos cubiertos por la Seguridad Social consistentes en defectos de rentas, el más importante, con mucho, es el de vejez. Y ello, porque se trata de una contingencia caracterizada por la frecuencia de su cristalización, al constituir el término previsible y normal de la vida profesional del individuo, tan sólo alterada por situaciones cuantitativamente irrelevantes de invalidez y muerte. Podemos decir, por tanto, que la jubilación es receptora, en términos generales, del conjunto de ciudadanos que se incorporan a la población activa, de ahí la importante dependencia de las estructuras demográficas de cada país y de los fenómenos que inciden sobre aquéllas. La característica referida viene agravada por el progresivo aumento de la esperanza de vida de la población lo que deriva en el creciente disfrute temporal de la pensión y su añadida necesidad de su revalorización periódica, de forma que las pensiones mantengan, al menos, su poder adquisitivo.

Conforme lo anterior, podemos afirmar que la jubilación constituye la médula espinal de cualquier sistema de protección social. Igualmente lo es, que su ordenación jurídica gira en torno al establecimiento de una edad fija o variable que articula el tránsito de la situación de activo a la situación de pensionista de jubila- 
ción. La edad se convierte así, en la llave maestra del sistema y adquiere por tanto connotaciones de especial relevancia. Precisamente por ello, hay que ser especialmente cuidadoso a la hora de redefinir la edad de jubilación, no sólo por la complejidad de la tarea en sí misma, sino por el entramado de condicionantes propios y ajenos o colaterales, presentes y futuros que actúan en un espacio múltiple de difícil y necesario equilibrio. La singularidad de los tiempos actuales está en que múltiples piezas del entramado global se han desencajado afectando al equilibrio del sistema y, por tanto, a su viabilidad. A todos estos temas me referiré a lo largo de las reflexiones que siguen.

\section{Demografia, Sistema de PENSIONES y COSTES: UnA APROXimaCión EN ClaVe EUROPEA}

Junto a los elementos descritos, debemos añadir otro de singular importancia, a saber, la ruptura del equilibrio o de la proporcionalidad entre el conjunto de ciudadanos que entran en la población activa y los que salen de la misma para acceder a la jubilación. Esta ruptura viene provocada por la disminución progresiva y notable de la tasa de natalidad (si bien en la parte baja de la pirámide de población es donde más diferencias existen entre los países de la UE, se da como promedio del número de hijos por mujer la cifra de 1,5 - siendo el umbral de la rotación generacional el 2,1- y se prevé una tasa de 1,6 para el 2030; en España, los datos más recientes, fijan el índice de fecundidad en 1,39 en el 2007, con una previsión para el 2017 de 1,46). No obstante, la disminución de la población nacional puede ser parcialmente compensada, como ha ocurrido en España en los años anteriores a la crisis, con el incremento de la población emigrante. Si bien los datos son muy desiguales en los países de la UE, en el periodo 1995-2007, España, Italia y el Reino Unido han recibido las tres cuartas partes de la migración europea ${ }^{471}$.

El incremento de la esperanza de vida fue tremendamente importante en los últimos cincuenta años (desde 1960, el incremento medio de la UE ha sido de 8 años, con una importante brecha entre Oriente y Occidente en la UE.27, y que en particular se refiere al hombre, que puede esperar vivir sólo hasta los 65-70 años en ocho de los Estados miembros de Europa central y oriental, en comparación con un promedio de más de 76 años en la UE-15) y lo seguirá siendo, aunque con menor intensidad, en el futuro (las previsiones en la UE, son de 5 años de aumento sobre el

${ }^{471}$ Commission of the European communities. Demography Report 2008, Brussels, SEC (2008)2911. La Comisión ha vuelto a realizar un Informe sobre el envejecimiento demográfico en el año 2009 (“Abordar los efectos del envejecimiento de la población de la UE”), basado en las previsiones presentadas por Eurostat 2008 donde de nuevo vuelve a replantear la transición demográfica que está viviendo Europa y los costes sociales de dicha realidad. Ver la Comunicación de la Comisión al Parlamento Europeo, al Consejo, al Comité Económico y Social Europeo y al Comité de Regiones de 29 de abril de 2009 (COM (2009) 180 FINAL- no publicado en el Diario Oficial 
dato actual hasta 2.050). Igualmente relevante es la esperanza de vida a los 65 años que se sitúa como media (UE.27) en 16,8 años para los hombres y 20,4 años para las mujeres, si bien la media es superada en los Estados del UE. $15^{472}$ De ello deriva una desconexión creciente entre las edades jubilatorias fijadas, en términos generales, durante la primera mitad del siglo XX, y la actual esperanza de vida a los 65 años, lo que exige medidas de reordenación que pueden tener, como veremos, distinto alcance y contenido. La importancia de la esperanza de vida ha provocado que en varios Estados de la UE, [ y en breve (posiblemente a partir del 2014) también en España] quede integrado en el cálculo de las pensiones iniciales de jubilación mediante la aplicación del denominado factor de equidad intergeneracional (factor de primera generación) ${ }^{473}$

Conviene también hacer referencia a los cambios en la intensidad de los flujos jubilatorios. Una característica notable con fecha en los calendarios europeos es la llegada a la jubilación de las generaciones del baby boom, esto es, de generaciones singularmente numerosas nacidas en Europa occidental y Estados Unidos después de la Segunda Guerra Mundial, en el periodo de 1946 a 1964. En España el fenómeno se retrasó hasta avanzados los años cincuenta, esto es, hasta el periodo comprendido entre 1957 y 1977. La mayor intensidad en el flujo jubilatorio ha encendido las luces de alarma, tanto por el impacto que en sí mismo provocará el fenómeno, como por la confluencia de una reducción de la población activa motivada por la bajada de las tasas de natalidad. Singularmente, cuando se anuncia que la ratio activos-pasivos fijada hoy es de aproximadamente cuatro personas en edad de trabajar por cada persona mayor de 65 años, en el futuro (2060), la ratio será sólo de dos activos ${ }^{474}$. Con todo, adviértase que si bien los problemas de los sistemas de pensiones son en gran medida de origen demográfico, las soluciones están lejos de ser "sólo" de carácter demográfico.

\footnotetext{
472 FUENTE: Europe in figures. Eurostat yearbook 2010.

${ }^{473}$ Sobre este factor puede verse el trabajo de MENEU GAYA, R.; DEVESA CARPIO, J. E.;; DEVESA CARPIO, M.; NAGORE GARCIA, A.; DOMINGUEZ FABIAN, I.; y ENCINAS GOENECHEA, B.:“El factor de sostenibilidad: diseños alternativos y valoración financiero-actuarial de sus efectos sobre los parámetros del sistema”. Revista Economía Española y Protección Social, 2013.

${ }^{474}$ Comisión Europea, Libro verde en pos de unos sistemas de pensiones adecuados, sostenibles y seguros, SEC (2010) 830.
} 


\section{Evolución de la relación de dependencia demográfica entre 2010 y 2060}

\section{España/Unión Europea}

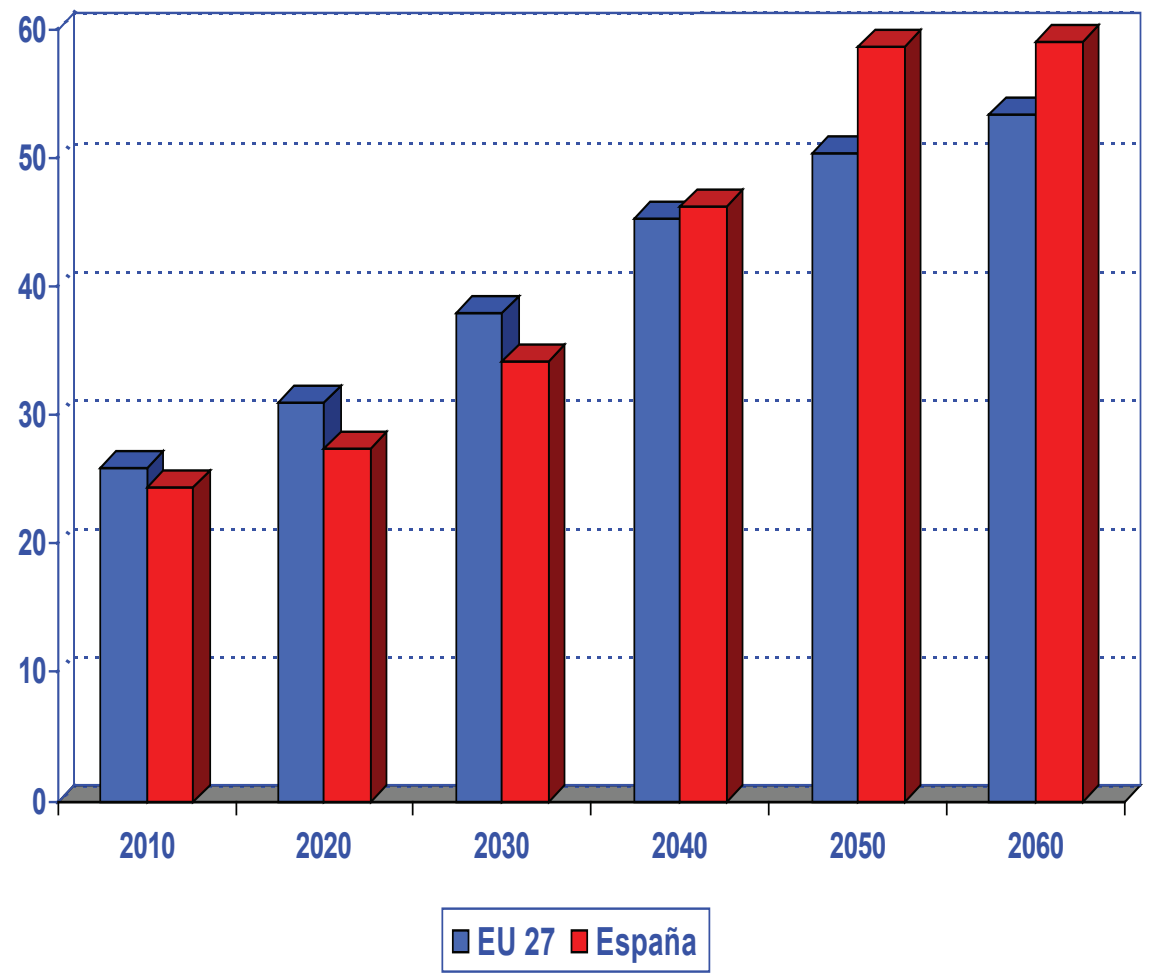

Todo lo dicho hasta aquí se deduce fácilmente del análisis de los cohortes de población en la UE, cuando se examinan comparativamente en la actualidad y en el futuro. Así, en la siguiente figura se puede observar como se incrementará el número de ciudadanos en las edades en que se accederá a la jubilación desde 2008 hasta 2060, con las consecuencias propias del incremento del número de pensiones, que ya se han señalado. 


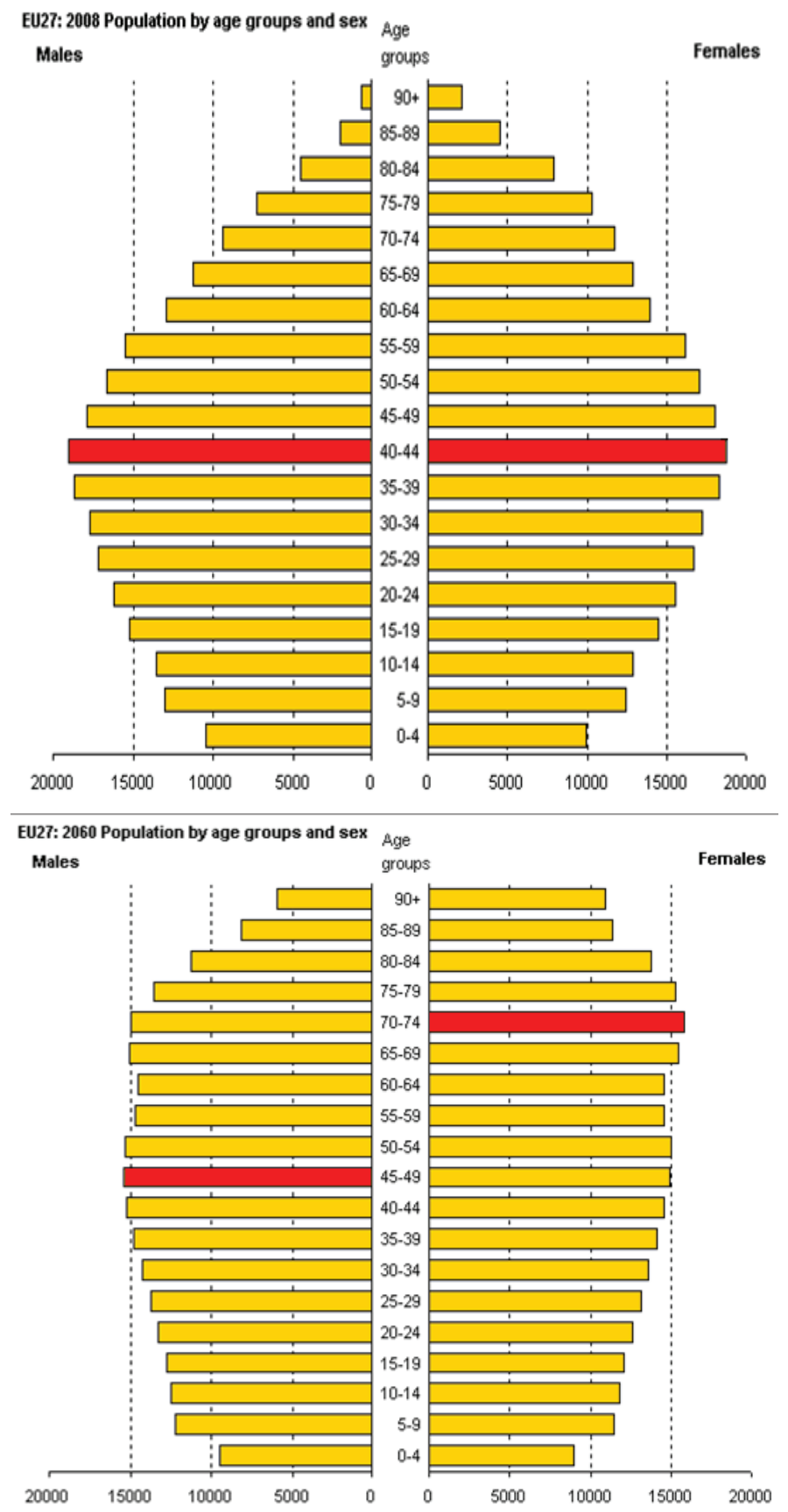

Fuente: European Comisión, Anexes to the Interim EPC-SPC Joint Report Pensions, Bruse- 
las, 2010.

Aunque parezca una obviedad, que lo es, debemos constatar que las generaciones que accedan a la jubilación, no llegan y se van, sino que se instalan con carácter definitivo, lo que implica que las pensiones deben ser revalorizadas - cualquiera que sea la formula, - con la finalidad de mantener su poder adquisitivo, de tal forma que provoca un efecto multiplicador sobre el gasto en pensiones de vital importancia. Posiblemente, la reordenación de sistema de revalorización de las pensiones está siendo el principal reto en la búsqueda de una mayor conexión con los parámetros de referencia que afectan a la situación económica del sistema y que impactan sobre su viabilidad futura. Constituye uno de los elementos del denominado "factor de sostenibilidad", que comienza a generalizarse en los países de la UE (factor de segunda generación) y también en España, a partir del 2014. Se trata con este factor (distinto del de longevidad) de asegurar los potenciales riesgos demográficos asociados a la tasa de dependencia ( $\mathrm{o}$, visto de otro modo, la ratio entre pensionistas y cotizantes), y los riesgos económicos de carácter estructural, a ésta materia me referiré más adelante.

El conjunto de datos y las reflexiones planteadas tiene su reflejo económico en términos de impacto sobre el PIB, lo que constituye un elemento de preocupación de la UE - y de los mercados financieros- que de forma reiterada (recientemente, 2006,2009 y 2012) advierte sobre los incrementos de gastos.

En los último informes (2009- 2012) ${ }^{475}$ se reconoce que, en términos generales, se producirá una disminución del número de ciudadanos en condiciones de trabajar ${ }^{476}$, que reducirá las cotizantes $\mathrm{y}$, consecuentemente, provocará la necesidad de soportar desde el sector público parte del coste del mantenimiento de la población con edades más avanzadas (pensiones, asistencia sanitaria y cuidados a los dependientes, entre otros).

Como consecuencia del envejecimiento de la población ${ }^{477}$, aumentará la necesidad de que el sector público proporcione transferencias y servicios relaciona-

${ }^{475}$ Todos los ratos referidos se encuentran cuantificados en los Anexos de la Comunicación de la Comisión al Parlamento Europeo, al Consejo, al Comité Económico y Social Europeo y al Comité de Regiones de 29 de abril de 2009 (COM (2009) 180 FINAL- no publicado en el Diario Oficial. Igualmente en el Libro Blanco, Agenda para unas pensiones adecuadas, seguras y sostenibles. COM (2012) 55 final, 16.2.2012

${ }^{476}$ No obstante, una primera conclusión consiste en la estimación de que en 2060 la población europea total será la misma, debido principalmente a los flujos migratorios y a la tasa de natalidad más alta de algunos de los países miembros respecto a otros. No obstante, dicha población tendrá una media de edad más avanzada.

477 A este respecto y motivado por la preocupación creciente del impacto demográfico en los sistemas de protección social, pueden verse el informe "Cambios demográficos y seguridad social: desafíos y oportunidades", elaborado por la Asociación Internacional de la Seguridad Social (AISS) en diciembre de 2010 y "Empleo y protección social en el nuevo contexto demográfico" elaborado por la OIT en el 2010. 
dos con la edad. Por consiguiente, se prevé que los efectos del envejecimiento de la población sobre el presupuesto serán substanciales en casi todos los Estados miembros, y se dejarán sentir ya en el transcurso de la próxima década.

Globalmente, sobre la base de las políticas actuales ${ }^{478}$, se prevé que el gasto público derivado del envejecimiento de la población aumente por término medio en aproximadamente 4,75 puntos porcentuales del PIB de aquí a 2060 en la UE, y en más de cinco puntos porcentuales en la zona euro, debido principalmente a los gastos en pensiones, asistencia sanitaria y en cuidados de larga duración. En todo caso, se advierte que el aumento del gasto público probablemente será muy significativo (igual o superior a siete puntos porcentuales del PIB) en nueve Estados miembros de la UE (Luxemburgo, Grecia, Eslovenia, Chipre, Malta, Países Bajos, Rumanía, España e Irlanda), aunque para algunos países este gran aumento se producirá a partir de un nivel relativamente bajo.

Si bien las previsiones realizadas por las instituciones de la UE se han visto alteradas por la crisis económica, son útiles como elemento de reflexión y de previsión de futuro. Con estos matices debe analizarse el cuadro que sigue.

\footnotetext{
${ }^{478}$ En el referido informe se cuantifican a la baja las previsiones respeto de Estados que han iniciado políticas de reformas de distinto alcance. Las reformas efectuadas por los países miembros de la Unión Europea sobre sus sistemas de pensiones han sido analizadas en el Informe "Avances y retos en la prestación de pensiones adecuadas y sostenibles en Europa", elaborado conjuntamente por las Comisiones de Política Económica y de Protección Social, de 7 de junio de 2010. Dicho Informe fue tomado en consideración por el Consejo en su reunión de 8 de noviembre de 2010 y constituye la base sobre la que se sustentan las consideraciones que en esa materia hacen el Libro Verde y el Libro Blanco.
} 


\section{Proyección del gasto público destinado a pensiones, expresado en porcentaje del PIB en los Estados miembros de la UE27 (2007-2060)}

\begin{tabular}{|c|c|c|c|c|c|c|c|c|}
\hline Pais & 2007 & 2010 & 2020 & 2030 & 2040 & 2050 & 2060 & $\begin{array}{c}\text { Variación } \\
2007 \cdot 2060 \\
\text { (en p.p.) }\end{array}$ \\
\hline Luxemburgo & 8.7 & 86 & 9.9 & 142 & 18,4 & 22.1 & 23,9 & 15.2 \\
\hline Alemania & 11.7 & 116 & 132 & 17.1 & 21.4 & 24 & 24.1 & 124 \\
\hline Chipre & 63 & 69 & 8.9 & 10.8 & 12.8 & 15.5 & 17.7 & 11.4 \\
\hline Rumania & 66 & 84 & 8,8 & 10,4 & 12.6 & 14.8 & 15,8 & 9.2 \\
\hline Eslovenia & 9.9 & 10.1 & 11.1 & 13,3 & 16.1 & 18.2 & 18,6 & 88 \\
\hline España & 8,4 & 8,9 & 9,5 & 10,8 & 13,2 & 15,5 & 15,1 & 6.7 \\
\hline Malla & 72 & 83 & 9,3 & 9.3 & 10.5 & 12 & 13.4 & 6.2 \\
\hline Belgica & 10 & 10,3 & 11.8 & 13,9 & 14,6 & 14.7 & 14,7 & 48 \\
\hline Noruega & 8.84 & 9.57 & 11.46 & 12.7 & 13.39 & 13.33 & 13.58 & 4.7 \\
\hline Irlanda & 4 & 4.1 & 4.6 & 5.4 & 6.4 & 8 & 86 & 46 \\
\hline Lituania & 68 & 6.5 & 6,9 & 8.2 & 9.1 & 10,4 & 11,4 & 46 \\
\hline Paises bajos & 66 & 65 & 7,8 & 9.3 & 10.3 & 10.3 & 10,5 & 4 \\
\hline Eslovaquia & 68 & 6.6 & 6.3 & 7.3 & 8.3 & 9.4 & 10.2 & 3.4 \\
\hline epública Che & 78 & 7.1 & 6,9 & 7.1 & 8.4 & 10,2 & 11 & 3,3 \\
\hline Finlandia & 10 & 10,7 & 12.6 & 13,9 & 13,6 & 13,3 & 13,4 & 3,3 \\
\hline Bubaria & 83 & 9,1 & 8,4 & 8.6 & 9.5 & 10,8 & 11,3 & 3 \\
\hline Hungria & 10.8 & 11,3 & $\pi$ & 11 & 122 & 13.2 & 13.8 & 3 \\
\hline Reino Unido & 66 & 67 & 6.9 & 7.6 & 8 & 8,1 & 93 & 2.7 \\
\hline Dinamarca & 10,4 & 10,2 & 10.5 & 11,5 & 12,1 & 12,3 & 12,8 & 2,3 \\
\hline Potugal & 11.4 & 119 & 124 & 126 & 125 & 13.3 & 13,4 & 21 \\
\hline Francia & 13 & 13.5 & 13.6 & 14.2 & 14.4 & 14.2 & 14 & 1 \\
\hline Austria & 12,8 & 12.7 & 13 & 13,8 & 13,9 & 14 & 13,6 & 0.9 \\
\hline Dinamaica & 9.1 & 94 & 10,6 & 10,6 & 10.4 & 96 & 92 & 0,1 \\
\hline Suecia & 95 & 96 & 9.4 & 9.5 & 9.4 & 9 & 94 & -0.1 \\
\hline Italia & 14 & 14 & 14.1 & 148 & 15.6 & 14.7 & 13.6 & .0 .4 \\
\hline Lelonia & 54 & 5,1 & 5,2 & 5,9 & 6,1 & 5,8 & 5,1 & $.0,4$ \\
\hline Estonia & 56 & 6.4 & 5,9 & 5.6 & 5,4 & 5,3 & 49 & .0 .7 \\
\hline Polonia & 11,6 & 10,8 & 9.7 & 9.4 & 9.2 & 9.1 & 88 & 2.8 \\
\hline
\end{tabular}

Fuente: Pacto de Toledo que recoge como fuente ;Comisión Europea, “Ageing report 2009”, tomado del informe elaborado por la Asociación de Instituciones de Inversión Colectiva y Fondos de Pensiones (inverco), diciembre de 2010.

Datos más recientes publicados por la Comisión Europea en 2012, reflejan que el gasto bruto en pensiones públicas en el 2010 en relación con el PIB (últimos datos disponibles en Eurostat),son los siguientes: para España se situó en el 10,7\%, quedando por debajo de la media de la zona euro (13,4\% del PIB) y de la UE-27 $(12,9 \%)$. Por países, oscila entre el 7,2\% del PIB en Irlanda y el 16\% de Italia. 


\section{GASTO EN PENSIONES (\% PIB)}

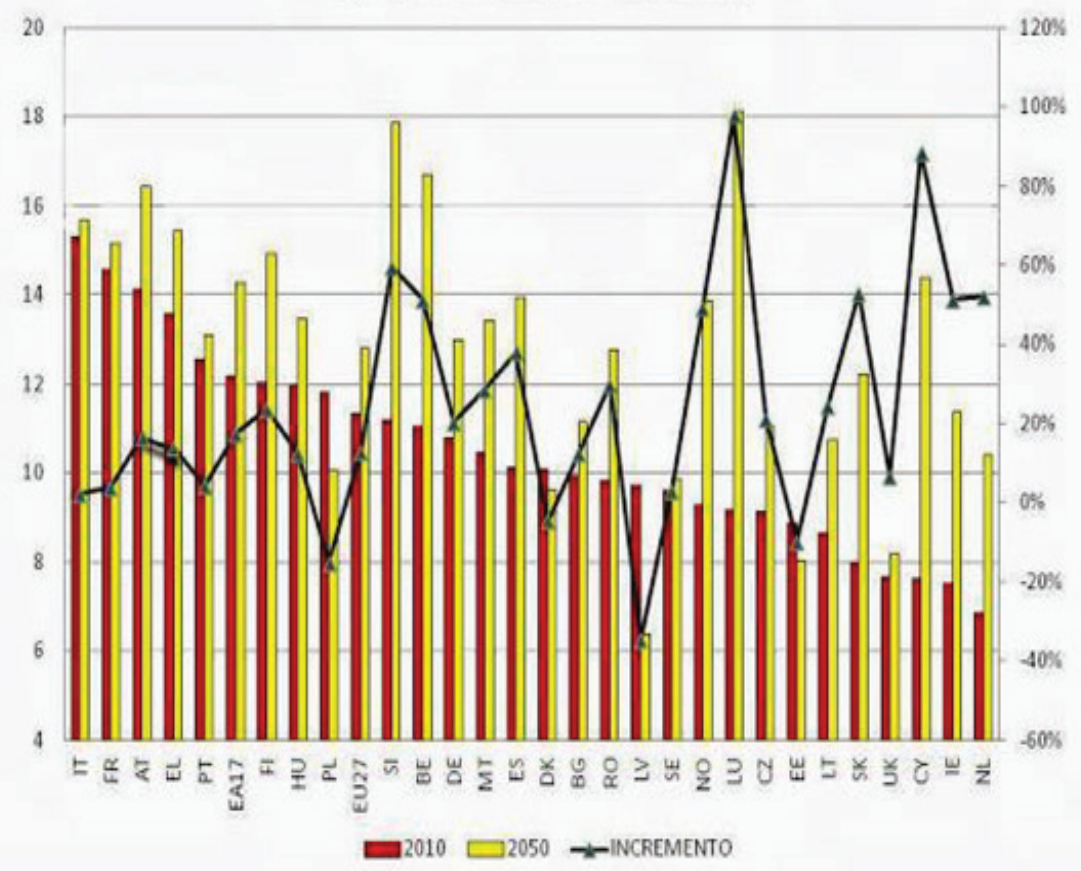

Fuente: EUROPEAN COMMISSION 2012 AGEING REPORT . Gasto en pensiones como porcentaje del PIB año 2010 y previsiones para el año 2050 (escala izquierda). Incremento esperado en el gasto en pensiones entre los años 2010 y 2050 como porcentaje del PIB (línea -escala derecha).

Con la idea de utilizar elementos diferenciales, conviene tener presente el gasto y las proyecciones para la UE.15, según el siguiente grafico 


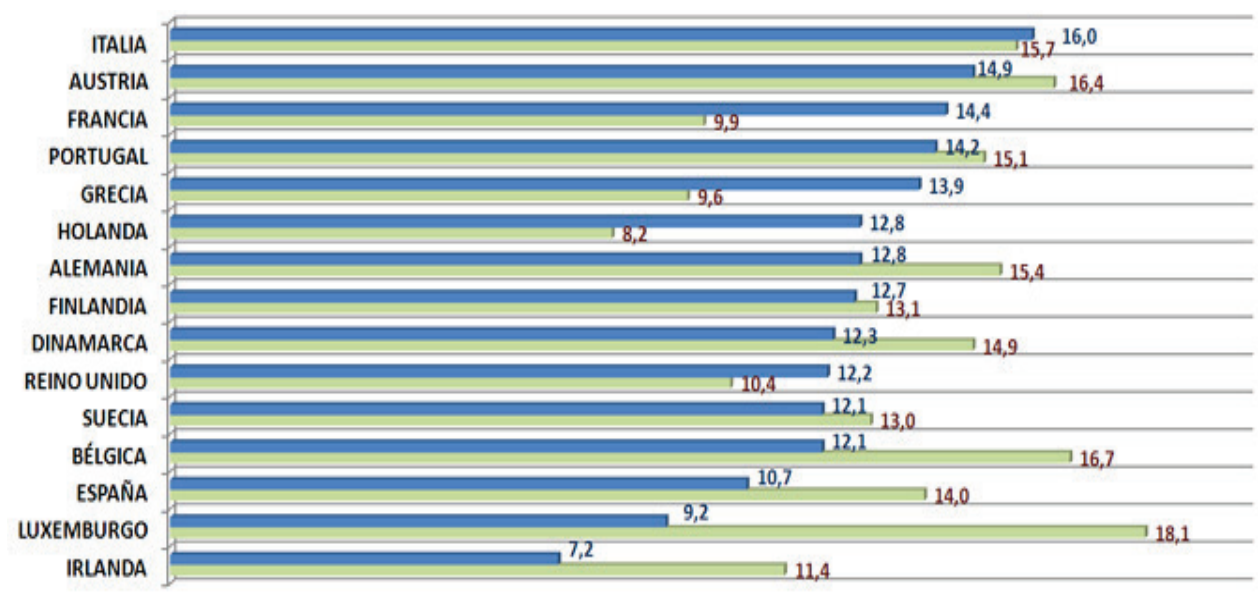

Fuente: Gasto bruto en pensiones públicas UE15 (\%PIB). 2010-2050. European commission 2012 ageing report

\section{REFLEXIONES SOBRE LA EDAD DE JUBILACION Y SU REFORMA}

La importancia del tema exige la revisión cautelosa y, a la vez, rigurosa de los parámetros que rodean la jubilación, entre ellos, todos los que confluyen en el entorno de la edad de jubilación ${ }^{479}$.

La edad de jubilación se ha convertido en los últimos treinta años en un concepto cíclicamente revisado ${ }^{480}$ y en continua experimentación, sobre el que inciden una multiplicidad de variantes ${ }^{481}$. Por un lado, los efectos de las sucesivas crisis

\footnotetext{
${ }^{479}$ Partiendo de la escasa atención que la propia Constitución española presta a la vejez, como así lo afirma con razón CARRIL VÁZQUEZ, JM, "El papel atribuido a la edad en la legislación laboral y de seguridad social española", en La relevancia de la edad en la relación laboral y de seguridad social, AAVV, CABEZA PEREIRO, J, BALLESTER PASTOR, Ma A., FERNÁNDEZ PRIETO, M., (dirs.), Thomson Reuters Aranzadi, Navarra, 2.009, pág. 364.

${ }^{480}$ ALONSO OLEA, M y TORTUERO PLAZA, JL. Instituciones de la Seguridad Social, Decimoctava edición, año 2.002, págs. 332 a 338.

${ }^{481}$ Como describe MALDONADO MOLINA, JUAN ANTONIO en "La edad de jubilación, retiro y vejez" en AAVV, MONEREO PÉREZ, JL y MALDONADO MOLINA, JUAN ANTONIO (Dirección y coordinación) La edad de jubilación, Editorial Comares, Granada, 2.011, pág. 85. "Clarificar qué es la vejez es una tarea compleja, ya que su definición adolece necesariamente de un fuerte relativismo: está en función de muy diversos factores (biológicos, socio-económicos, culturales, ideológicos, psicológicos, médicos, antropológicos), y condicionada por la perspectiva con que cada uno afronte la cuestión, tanto desde un punto de vista profesional como personal: según su propia actitud vital y los valores sociales, éticos y religiosos imperantes en su entorno"
} 
económicas, de las transformaciones en los modos de producción, de la composición y estructura del mercado de trabajo, de la globalización de las economías y de los mercados, del paro creciente o sostenido ${ }^{482}$... Por otro, las ya apuntadas y referidas al envejecimiento de la población, en sus distintas dimensiones ${ }^{483}$. Y finalmente, el impacto de todas ellas sobre los problemas actuales y futuros de financiación de los sistemas de pensiones ${ }^{484}$. Todas estas variantes hacen oscilar la relación dominante entre política de empleo y política de pensiones, sin que se haya llegado a un punto de equilibrio ${ }^{485}$, lo que impacta sobre las relación necesaria entre los ciclos vitales y la proyección protectora de los sistemas de pensiones ${ }^{486}$.

No cabe duda, que en los tiempos actuales la fijación de la edad de jubilación debe efectuarse teniendo en cuenta la esperanza de vida de los ciudadanos.

${ }^{482}$ A este respecto, GARCÍA VIÑA, JORDI. “¿Cómo afecta la crisis económica a los modelos actuales europeos de Seguridad Social?" en AAVV, El futuro europeo de la protección social, Laborum, Murcia, 2.010.

483 La propia Exposición de Motivos de la Ley 27/2011, afirma que "la disminución prolongada de las tasas de natalidad y el simultáneo incremento de la esperanza de vida de las personas mayores está provocando una inversión de la estructura de la pirámide de población, aumentando el número de pensionistas en relación con la población activa, esto es, variando la tasa de dependencia de los pensionistas. De no modificarse, aún parcialmente, esta tendencia mediante el incremento de las tasas de natalidad y de los flujos migratorios, la misma se acentuará en las próximas décadas, por la propia evolución demográfica. Esta tendencia demográfica afecta a todas las generaciones, pero sobre todo a las más jóvenes, por el hecho de que serán estas generaciones jóvenes las que serán mayores de sesenta y cinco años durante más tiempo.

${ }^{484}$ Sobre este aspecto, MALDONADO MOLINA, J A. "La edad de jubilación, retiro y vejez", Op. Cit., Pág. 85-120.

${ }^{485}$ El desequilibrio y las contradicciones son gráficamente dibujadas por OLARTE, al afirmar que "Por un lado, nos encontramos con unas medidas de fomento del empleo que pretenden contrarrestar la situación desventajosa en el mercado de trabajo de los trabajadores de edad avanzada...con otras, que presuntamente, pretenden proceder a un mas equitativo reparto generacional del empleo (prejubilaciones, jubilaciones anticipadas incentivadas o forzosas) ..y por otro lado, en sentido contrario las políticas y el derecho de la seguridad social empeñados en fomentar el alargamiento de la vida activa" OLARTE ENCABO, S, Edad y empleo. Colectivos desfavorecidos, en AAVV (Dir, CABEZA PEREIRO,J, BALLESTER PASTOR, $\mathrm{M}^{\mathrm{a}}$ A. FERNANDEZ PRIETO, M), La relevancia de la edad...cit. Pag.94

${ }^{486}$ Por todos, MONEREO PEREZ JL. Ciclos vitales y Seguridad Social: trabajo y protección social en una realidad cambiante, Revista Ministerio de Trabajo e Inmigración, núm. Extraordinario 74, 2008, pags. 49-134 y MONEREO PÉREZ, JL. "La política de pensiones tras el acuerdo social y económico de 2.011: La fase actual de la construcción de un "nuevo" sistema de pensiones" en AAVV, MONEREO PÉREZ, JL y MALDONADO MOLINA, JUAN ANTONIO (Dirección y coordinación) La edad de jubilación, Editorial Comares, Granada, 2.011, pág. 27 
Y ello, porque con la financiación actual y con la futura ${ }^{487}$, hoy planteada, cabe el peligro de que los Sistemas de Seguridad Social - que son y han sido parte esencial de nuestra cultura y del progreso económico ${ }^{488}$ - tengan dificultades para soportar el pago creciente de pensiones de jubilación, suficientes y revalorizadas, durante largos períodos de tiempo ${ }^{489}$. En este orden de cosas es necesario redefinir los espacios de imputación de la protección social, distinguiendo claramente los que responden a las cotizaciones sociales en un sistema financiero de reparto. Claridad que permitirá ponderar adecuadamente los medios de financiación desde una concepción autónoma de la seguridad social y dar un contenido real al término "contributividad". Clarificación que, en modo alguno, impide la fijación de fuentes complementarias de financiación ${ }^{490}$, o mejor y además una nueva redistribución de las mismas aligerando los impuestos sobre la nómina para aumentar la productividad e incorporar fuentes procedentes del capita ${ }^{491}$.

487 Por las razones anunciadas en el texto, el Artículo 8 de la Ley 27/2011, cuyo análisis realizo en el incorpora a la LGS una Disposición adicional quincuagésima novena, bajo la rúbrica "Factor de sostenibilidad del sistema de la Seguridad Social". Con el objetivo de mantener la proporcionalidad entre las contribuciones al sistema y las prestaciones esperadas del mismo y garantizar su sostenibilidad, a partir de 2027 los parámetros fundamentales del sistema se revisarán por las diferencias entre la evolución de la esperanza de vida a los 67 años de la población en el año en que se efectúe la revisión y la esperanza de vida a los 67 años en 2027. Dichas revisiones se efectuarán cada 5 años, utilizando a este fin las previsiones realizadas por los organismos oficiales competentes.

${ }^{488}$ Con frecuencia olvidamos el significado e impacto económico de la seguridad social en todas sus dimensiones, en este sentido, ver ZUBIRI ORIA, I. "Un análisis económico de la Seguridad Social”. AAVV (Dir. TORTUERO PLAZA,JL). Cien años de protección social en España. Libro conmemorativo del I centenario del Instituto Nacional de Previsión. Ministerio de Trabajo y Asuntos Sociales. Madrid, 2.007.

${ }^{489}$ La dinámica de estos dos factores, viabilidad financiera y evolución demográfica, condicionan el diseño de la estructura del sistema y su objetivo de ofrecer una protección suficiente a los trabajadores en situación de necesidad. En este sentido, MONEREO PÉREZ, J.L. "Reestructuraciones de empresas y edad de jubilación: Una reforma necesaria", en AAVV, MONEREO PÉREZ, J.L. (Dir.). La política de pensiones en el Estado social en transformación. Aspectos crítcicos. Granada, Comares, 2.010, pág. 146.

${ }^{490}$ La disposición adicional undécima de la Ley 27/2011, refiere expresamente a las alternativas de financiación complementaria, disponiendo que "Los Ministerios de Trabajo e Inmigración y de Economía y Hacienda y los agentes económicos y sociales, examinarán, en el marco de las recomendaciones del Pacto de Toledo, la conveniencia de establecer posibles escenarios de financiación complementaria de nuestro sistema de Seguridad Social en el medio y largo plazo".

491 "El mantenimiento de las fuentes de financiación y la falta de iniciativas alternativas previstas ha venido siendo una de las limitaciones más significativas del proceso de reforma que se viene acometiendo desde el Pacto de Toledo y sus revisiones sucesivas. Tan sólo el 
Si bien el punto de partida en los distintos Estados de la Unión Europea es diferente, lo cierto es que, desde hace algunos años, se ha consolidado, entre otras, una serie de tendencias agrupadas en los siguientes bloques: a) elevación ponderada de la edad de jubilación con criterios igualitarios para hombres y mujeres; b) desincentivación o penalización de las jubilaciones anticipadas; c) fomento o incentivación del retraso en el acceso a la jubilación; d) endurecimiento de las exigencias contributivas mediante reformas paramétricas; e) reformas sistémicas que pretenden, de forma voluntaria u obligatoria, redistribuir riegos entre lo público y lo privado, esto es, entre el mercado y la sociedad; f) incorporación de factores de sostenibilidad, bien referidos a la esperanza de vida, bien a la revalorización de las pensiones.

Aunque todas las tendencias forman parte de un "todo", cada una tiene su propia problemática y ofrece márgenes de actuación distintos. Con todo, las reformas deben ser de protección larga donde se conviven, en un sistema de prestación definida, el ayer, el hoy y singularmente el mañana ${ }^{492}$.

Si nos referimos a la edad de jubilación y nos situamos en la edad emblemática de los 65 años, nos damos cuenta de que el margen de actuación de cada Estado es distinto condicionando el impacto más o menos traumático de las medidas. Cierto es, que se ha producido una evolución paulatina de las edades de jubilación en la generalidad de los Estados, sin embargo también lo es, que el punto de partida era diferente. No es lo mismo moverse entre los 60 y los 65 años que superar la edad "talismán" de los 65 años. Con todo, el margen de actuación hacia el futuro es cada vez menor, en la medida en que durante los últimos quince años se ha recortado el espacio hacia la edad de 65 años. De esta forma, si el resto de las medidas no producen efecto, tendremos - y así lo ha hecho España con la Ley 27/2011- que cambiar la "edad emblemática", lo que ya han comenzado a diseñar distintos Estados de la Unión Europea (Alemania, Reino Unido, Dinamarca, Irlanda, Suecia, entre otros) que con fórmulas distintas y de aplicación progresiva elevan el umbral jubilatorio hacia los 67 años, asociando generalmente su impacto con la llegada de las generaciones del baby boom.

En este orden España cuenta con una posición privilegiada en términos tem-

Acuerdo de 2.011 parece recoger alguna mención a propósito de las posibles alternativas de financiación complementaria de nuestro sistema de Seguridad Social en el corto y medio plazo" MONEREO PÉREZ, JL. "La política de pensiones tras el acuerdo social y económico de 2.011: La fase actual de la construcción de un "nuevo" sistema de pensiones". Op. Cit. Pág. 7 .

492 Esta claridad de ideas en MONEREO PÉREZ, JL. "El ciclo largo de la reforma de la seguridad social: significación técnica y político jurídica del proceso de reforma legislativa actual" La reforma de la Seguridad Social. Estudio sistemático de la Ley 40/2007 de 4 de diciembre, de medidas en materia de Seguridad Social. Editorial La Ley. Madrid, 2.008, asi como en GARCÍA MURCÍA, J. "La política contemporánea de jubilación: algunos dilemas y algún contrasentido" Tratado de jubilación. Homenaje al Profesor Luis Enrique de la Villa Gil. Iustel, Madrid, 2.007. 
porales, en la medida en que la presión demográfica ejercida por las generaciones del baby boom se producirá con efectos retardados, lo que nos debería permitir afrontar las reformas necesarias desde una posición más sosegada y teniendo en cuenta las experiencias de los Estados europeos donde el impacto de las referidas generaciones está próximo.

Sin embargo las teorías han dado paso a las realidades impuestas por la presión de los mercados financieros ${ }^{493}$, que buscan o imponen su llamada "confianza" en reformas inmediatas que podríamos llamar de "impacto escénico o mediático", que no siempre producen los efectos reales anunciados y necesarios, como veremos más adelante ${ }^{494}$.

Sin duda los sistemas de pensiones deben enfrentarse a dos retos importantes, la elevada esperanza de vida de los ciudadanos y la llegada de las masivas generaciones del baby boom. No obstante, los retos referidos no son ajenos a un sin fin de variantes, que van desde los niveles de crecimiento económico y productividad ${ }^{495}$, hasta alcanzar unas tasas de ocupación razonable de hombres y mujeres a partir de los 55 años, lo que viene siendo un objetivo constante de la UE.

${ }^{493}$ En el mismo sentido, LOPEZ CUMBRE, afirma que "La Ley $27 / 11 \ldots$ constituye un ejemplo más de esa legislación negociada, condicionada, impuesta o "exigida" por la Unión Europea a la que se hacía referencia, entre otras razones, con el fin de evitar consecuencias económicas y financieras desfavorables para España semejantes a las que, antes o después, sufrirían Grecia, Portugal e Italia, por este orden" LOPEZ CUMPRE, L. La reforma de la jubilación, Revista General de Derecho del Trabajo y Seguridad Social, núm 29-30 (extraordinario) junio/2012 http://www.iustel.com/v2/revistas/detalle_revista.asp?id_noticia $=412140$ ${ }^{494}$ En esta línea son sumamente ilustrativas las consideraciones previas que realiza MOLINA NAVARRETE, sobre la reforma de la negociación colectiva, MOLINA NAVARRETE, CRISTOBAL, La decretada reforma de la negociación colectiva: ¿el último botín" de los mercaderes del templo, en Revista de Trabajo y Seguridad Social, CEF, núm. 340, julio 2011, pags.8-9.

${ }^{495}$ El sistema de seguridad social no es un sistema cerrado donde únicamente el juego de determinados factores conduzca a un resultado positivo o negativo de sus cuentas. Por el contrario, se trata de un sistema dinámico donde elementos como la evolución de la productividad tienen una importancia significativa en la consecución de equilibrio presupuestario. En este sentido, DE LA FUENTE LAVÍN, MIKEL, en "La flexibilidad en la jubilación", AAVV, MONEREO PÉREZ, JL y MALDONADO MOLINA, JUAN ANTONIO (Dirección y coordinación) La edad de jubilación, Editorial Comares, Granada, 2.011, pág. 447-448, expone que "La recuperación de los incrementos de la productividad a favor de los asalariados permite financiar el aumento del gasto en pensiones $\mathrm{y}$, además, queda margen disponible para el necesario incremento en otras partidas del gasto social, el aumento de los salarios y la reducción del tiempo de trabajo". 


\section{TIEMPOS DE CRISIS VERSUS TIEMPOS DE REFORMAS ${ }^{496}$}

Afirmar que el sistema de pensiones tiene problemas, no es nada nuevo. Los tuvo en el pasado, los tiene en el presente y los tendrá en el futuro. Las crisis económicas y sus efectos han sido y son un permanente "compañero de viaje". No obstante, ahora damos especial relevancia y la tiene, a otros factores. Por un lado, se está produciendo un envejecimiento de la población española, que como es conocido se incrementará con la llegada a la edad de jubilación de las cohortes del baby boom, derivando en un desequilibrio de la relación entre pensionistas y cotizantes. Por otro, se está produciendo un incremento constante de la esperanza de vida, lo que supone una extensión del tiempo en que se percibe la pensión y, por tanto, un incremento del gasto en pensiones.

Nótese que ninguno de los problemas apuntados es nuevo. Desde hace décadas sabemos y así se ha venido advirtiendo hasta la saciedad, que los factores demográficos producirían sus efectos. El rosario de factores determinantes es sobradamente conocido, bajísima tasa de natalidad, incremento constante de la esperanza de vida, existencia de generaciones especialmente numerosas, las del baby boom, etc. Sus efectos, como hemos apuntado, también eran y son sobradamente conocidos. A todos ellos se unen los propios de la crisis económica, destrucción masiva de empleo, reducción de salarios y cotizaciones, precipitación de jubilaciones anticipadas, aumento de gasto en desempleo... en definitiva, menos ingresos y mayores gastos. La crisis no solo ha puesto de manifiesto sus propios efectos, sino que ha despejado el bosque para que los factores demográficos renazcan con su mayor nitidez y dureza.

Los tiempos más duros de la crisis, con una destrucción de empleo sin precedentes, no son los más adecuados para afrontar reformas superpuestas, o reducciones de las pensiones sobre pensiones ya reducidas o endurecimiento de requisitos configuradores (edad, tiempo de cotización, cálculo de la pensión, jubilaciones anticipadas...) sobre requisitos ya endurecidos.

El sistema de protección social está demostrando que constituye un factor social de primer orden para atemperar los gravísimos efectos de la crisis, donde cada parcela de protección está cumpliendo adecuadamente su función social, desde la protección por desempleo, hasta las pensiones que dan cobertura no sólo a sus titulares, sino a los núcleos familiares dependientes; sin estos espacios estrictos y amplios de protección la situación social sería insostenible.

Igualmente, la crisis ha demostrado que el carácter dinámico de nuestro sistema le confiere una capacidad de adaptación a las situaciones de crisis (la actual

${ }^{496}$ Una primera versión de las reflexiones de los apartado de este epígrafe la efectué en TORTUERO PLAZA, J.L, La construcción de la reforma de la jubilación y el factor de sostenibilidad: imperfecciones y trampas. Ponencia a las XVII Xornadas de Outono de Vigo (11/2013), ACTUM SOCIAL núm. 83/2014 (, Ed.Francis Lefebvre). 
y las pretéritas) sin parangón con respecto a otros sistemas. No hay duda por tanto y lejos de catastrofismos, que el sistema sabrá y podrá adaptarse a los nuevos retos demográficos.

A lo anterior debemos añadir el impacto económico del sistema de protección, siempre importante y ahora vital, en la medida en que la situación propicia que la práctica totalidad de las prestaciones recibidas se dedique al consumo propio y ampliado.

Con la idea de fijar el escenario, conjuntamente con la destrucción de tejido productivo y de empleo (que parece no cesar en el corto plazo y no recuperarse sustancialmente en el medio plazo, según las previsiones del Gobierno), habría que hacer referencia a la reducción salarial producida en los últimos años, a los retrasos constantes ( y con frecuencia irrecuperables) en el percibo del salario, la congelación (plena o parcial) de las pensiones y los efectos reductores de las pensiones propiciados por las reformas, la elevación generalizada de impuestos, el encarecimiento ( $\mathrm{y}$ las restricciones) en el acceso a servicios públicos ... etc.

No parece que el escenario actual sea el más propicio para afrontar reformas que precipiten y/o endurezcan (reducción adicional) las pensiones. Todo ello, sin perjuicio del "efecto expulsión", (desprotección) que habitualmente no se tiene en cuenta.

Con la finalidad de ofrecer un marco global de las reformas presentes y futuras anunciadas, conviene aproximarnos a sus planteamientos generales abordando las sucesivas fases y su valoración.

\subsection{LA REFORMA DE LA JUBILACIÓN EN LA LEY 27/2011, SOBRE ACTUALIZACIÓN, adecuación y Modernización del Sistema de la Seguridad Social}

La Ley 27/2011, sobre actualización, adecuación y modernización del sistema de seguridad social, inicio su andadura legislativa en un claro escenario de consenso político y social. En efecto, el proyecto de reforma estuvo precedido por la renovación del Pacto de Toledo ${ }^{497}$ y la firma del Acuerdo Social y Económico para el crecimiento, el empleo y la garantía de las pensiones ${ }^{498}$, suscrito por el Gobierno, la CEOE, CEPYME, CCOO y la UGT, retomando así el escenario de consenso que propicio la reforma del 2007 en materia de seguridad social ${ }^{499}$.

${ }^{497}$ En este sentido, MONEREO PÉREZ, J L, "El sistema de pensiones en el marco de la nueva revisión y actualización del Pacto de Toledo", Aranzadi Social: Revista Doctrinal, $\mathrm{n}^{\circ}$ 15 , diciembre, 2.010 , pág. 58 y ss.

${ }^{498}$ Un análisis del Acuerdo en CAVAS MARTÍNEZ, F. Y el dialogo social dio sus frutos, en Aranzadi Social, núm. 22/2011, págs. 11-24 y MONEREO PÉREZ,JL. La reforma concertada de las pensiones. el Acuerdo Social y Económico de 2011 y su desarrollo legislativo, Rev. De Derecho del Trabajo y Seguridad Social,(Iustel) núm. 25, mayo 2011

499 Una visión general de la evolución de nuestra seguridad social al hilo de la historia de los 
Conviene resaltar que han quedado fuera de la Ley partes importantes del Acuerdo Social y Económico, básicamente y por lo que aquí interesa, las referidas a las políticas de empleo de trabajadores de mayor edad, que constituyen la otra cara de la moneda y condicionan la efectividad de la misma reforma ${ }^{500}$. A esta materia refería el Acuerdo bajo el titulo "Estrategia global para el empleo de los trabajadores de más edad",

Agotándose la legislatura y, por tanto, con impacto más bien testimonial, se aprobó el marco de las políticas de empleo mediante Acuerdo del Consejo de Ministros de 28 de octubre de 2011 sobre la Estrategia Global para el Empleo de los Trabajadores y las Trabajadores de Más Edad 2012-2015 (en adelante, Estrategia 55 y más) . La Estrategia 55 y más constituye el marco general de la intervención de los poderes públicos en materia de empleo de trabajadores de edad, y extenderá su vigencia a lo largo del trienio 2012-2014, coincidiendo con la vigencia de la Estrategia Española de Empleo.

Siguiendo la línea de reformas paramétricas iniciadas en otros Estados de la UE, la Ley española proyecta los cambios más significativos en las siguientes materias: la edad de jubilación, los elementos que integran el contenido económico de la prestación y las jubilaciones anticipadas, tanto plenas, como parciales. La jubilación, es por tanto y con toda lógica, la estrella o el núcleo duro de cualquier sistema de pensiones ${ }^{501}$. El alcance de la reforma afecta en forma gráfica a los siguientes

Pactos de Toledo, puede verse en el ejemplar e ilustrativo trabajo de PANIZO ROBLES, J A. "Dos décadas de reformas de la Seguridad Social: del Pacto de Toledo de 1.995 al Acuerdo Social y Económico de 2.011", Revista de Trabajo y Seguridad Social, Centro de Estudios Financieros, $n^{\circ} 336,2.011$, pág. 77.

${ }^{500}$ En esta línea, ESTEBAN LEGARRETA,R. Jubilación y políticas de empleo. Un análisis de la reforma de la jubilación en clave de empleo (http://www.iuslabor.org/jornades-i-seminaris/ponencies/)

501 Sobre la reforma ver, AA. VV. (García-Perrote, I., Mercader Uguina, J. R., Directores). La reforma de la Seguridad Social 2011. Valladolid (Lex Nova), 2011; AA. VV. (Monereo Pérez, J. L y Maldonado Molina, J. A., Dirección y Coordinación). La edad de jubilación. Granada (Comares), 2011.GETE CASTRILLO, P.: - La reforma de pensiones de 2011: procedimiento y contenidos (I y II) Relaciones Laborales núm. 20, 2011, pág. 12 ; LÓPEZ GANDÍA, J. y TOSCANI GIMÉNEZ, D.: La reforma de la jubilación. Comentarios a la Ley 27/2011 de 1 de agosto, Valencia, Tirant lo Blanch, 2011; PÉREZ ALONSO, M ${ }^{\text {a }}$ A.: - La nueva pensión de jubilación y otras reformas en el sistema de Seguridad Sociall Aranzadi Social, núm. 9/2012, (BIB 2011/1761); ESTEBAN LEGARRETA,R. Jubilación y políticas de empleo. Un análisis de la reforma de la jubilación en clave de empleo (http://www.iuslabor.org/jornades-i-seminaris/ponencies/); SEMPERE NAVARRO, A.V.: Actualización del sistema de Seguridad Social. Una visión sinóptica y global de la Ley 27/2011 (I), (II), en AS $n^{\circ}$ 6/2011 y n 7/2011; TORTUERO PLAZA, J.L.:" La pensión de jubilación en el Proyecto de Ley sobre actualización, adecuación y de modernización ( I y II)", en Revista de Aranzadi social $\mathrm{n}^{\mathrm{o}} 3$ y 5/ /2011, pp. 4 y ss.; SEMPERE NAVARRO, A.V y FERNANDEZ ORICO, 
parámetros:

$>\quad$ La edad de jubilación que evoluciona desde los 65 años a los 67 en una progresión paulatina entre el año 2013 y el año 2027.

$>\quad$ La edad de las jubilaciones anticipadas y de la jubilación parcial, que evolucionan (tras la reforma operada por el RDL 5/2013) con la misma secuencia que la edad general.

$>\quad$ Se reduce la tasa de sustitución de la pensión (reducción de la pensión), al endurecerse los siguientes parámetros:

- Elevación del número de años exigibles para obtener el 100 por 100 de la pensión, que evoluciona desde los 35 años a los 37 años.

○ $\quad$ El sistema de cálculo de la pensión de jubilación, ampliándose el número de años computables para la determinación de la base reguladora de la pensión desde los 15 a los 25 años.

○ Igualmente se aminora el "valor" de cada año de cotización, a efectos de fijar la cuantía de la pensión.

- Se endurece respecto a la situación anterior el sistema de integración de lagunas en la base reguladora.

Característica de la reforma, consustancial a la seguridad social, es su aplicación lenta y progresiva, que se inicia en el año 2013 y se proyecta, según las materias, hasta el año 2022 o 2027. La reforma pretende, siguiendo el criterio de otros Estados de la EU, que su proyección temporal esté concluida para recibir a las generaciones del baby boom, esto es, las nacidas a partir de 1957, que cumplirán los 65 años en el año 2022, aunque el mayor impacto se producirá con la llegada de los nacidos a mediados de los años 60, cuando la Ley este plena aplicación.

F.J.: Reforma y modernización de la Seguridad Social. Aranzadi, 2012; TOSCANI: La reforma de la jubilación a edad ordinaria por la Ley 27/2011, en Aranzadi social $\mathrm{n}^{\circ}$ 7/2011; GONZÁLEZ ORTEGA, J.: "Las nuevas edades de jubilación y sus efectos en la cotización y en la cobertura", en Revista General de Derecho del Trabajo y Seguridad Social n' 29-30 (2012);TORTUERO PLAZA, JL, La reforma de la Jubilación, Pamplona, edit. Aranzadi, 2012; VILLA GIL, LE. La reforma de la composición del Sistema de Seguridad Social y del modelo de protección social, Revista General de Derecho del Trabajo y Seguridad Social, núm 29-30 (extraordinario) junio/2012; LOPEZ CUMPRE, L. La reforma de la jubilación , Revista General de Derecho del Trabajo y Seguridad Social, núm 29-30 (extraordinario) junio/2012; MONEREO PEREZ,JL y MALDONADO MOLINA,JA, La reforma de la jubilación, Revista General de Derecho del Trabajo y Seguridad Social, núm 29-30 (extraordinario) junio/2012 


\subsection{LA IMPLANTACIÓN DEL FACTOR DE SOSTENIBILIDAD}

\subsubsection{Antecedentes: La creación del Comité de Expertos}

El Gobierno anunció que para el mes de septiembre llevaría al Parlamento la Ley que creara el factor de sostenibilidad, posiblemente con la idea de implantarlo a partir del 1 de enero de 2014. La aceleración viene impuesta por las instancias Europeas. En efecto, el día 28 de Junio de 2013, el Consejo Europeo aprobó las Recomendaciones por países y, concretamente para España, una especialmente importante en materia de pensiones cuyo tenor es el siguiente: "culminar al final de 2013 a más tardar la regulación del factor de sostenibilidad, a fin de garantizar la estabilidad financiera a largo plazo del sistema de pensiones, aumentando, entre otras cosas, la edad efectiva de jubilación, ajustando la edad de jubilación o el pago de las pensiones de jubilación a las modificaciones de la esperanza de vida".

De esta forma, por Acuerdo de Consejo de Ministros de 12 de abril de 2013, se crea un Comité de Expertos ${ }^{502}$ para que realice un informe donde se defina el factor de sostenibilidad del sistema de la Seguridad Social, en el marco legal referido.

El 7 de junio de 2013 el Comité aprobó ${ }^{503}$ y presento el Informe. Sin entrar en el entramado de las formulas, el Informe expone la finalidad del factor de sostenibiliadad y su contenido en los siguientes términos:

"El factor de sostenibilidad está diseñado para que los desequilibrios del sistema de pensiones se puedan anticipar cada año de manera transparente y se neutralicen de una forma distribuida en el tiempo. Los principales tributos que el factor de sostenibilidad puede rendir a la sociedad española son, por una parte, la transparencia y la predictibilidad de las pensiones; por otra, un mecanismo de corrección automático de errores distribuido en el tiempo, y por tanto, aceptable en sus consecuencias.

El factor se compone, en primer lugar, de un Factor de Equidad Intergeneracional (FEI) que busca que las condiciones de las pensiones sean iguales para todos los jubilados, con independencia de la cohorte demográfica a la que pertenezcan, algo que no ocurre en la actualidad. En segundo lugar, consta de un Factor de Revalorización Anual (FRA) que al proceso, digamos, natural de evolución de la

${ }^{502}$ Integrantes del Comité: Víctor Pérez-Díaz (Presidente), Manuel Lagares Calvo, José María Marín Vigueras, Santos Ruesga Benito, Miguel Ángel Vázquez Burgos, Ignacio Conde Ruiz, Rafael Doménech Vilariño, José Enrique Devesa Carpio, Mercedes Ayuso, Miguel Ángel García Díez, Francisco Castellano Real, José Luis Tortuero Plaza.

${ }^{503}$ El Informe se aprueba con 10 votos a favor, 1 voto en contra (Santos Ruesga) 1 abstención (Tortuero) y se presentaron 3 votos particulares ( Ruesga, Tortuero -http://estaticos. elmundo.es/documentos/2013/06/07/voto_tortuero.pdf y García Díaz) 
pensión media, une una corrección basada en la relación entre ingresos y gastos del sistema de pensiones. Sucintamente, cuando los gastos crecen más que los ingresos, el FRA frena el crecimiento natural de la pensión; en las situaciones contrarias, lo expande. Para evitar que la revalorización de las pensiones aboque a los pensionistas a sacrificios poco tolerables en las fases bajas de la economía, el FRA no se calcula con cifras de un solo año, sino de un conjunto de años que abarquen, en la medida de lo posible, la totalidad del ciclo económico, y, en caso de desequilibrio, permite la corrección, no de golpe, sino a lo largo de varios años" ${ }^{204}$.

Defendido el Informe y los votos particulares en la Comisión del Pacto de Toledo del Congreso de los Diputados y remitido a los Interlocutores Sociales, solo quedaba esperar al Proyecto de Ley del Gobierno presente en el Congreso de los Diputados.

3.2.2. El proyecto de Ley y la Ley 23/2013, de 23 de diciembre, reguladora del Factor de Sostenibilidad y del Índice de Revalorización del Sistema de Pensiones de la Seguridad Social

En este orden, el Gobierno presento el Proyecto de Ley sobre el factor de sostenibilidad, iniciando los trámites correspondientes. El Proyecto, como era de esperar y advertí continuamente en la Comisión de Expertos ha levantado el rechazo generalizado de los ciudadanos, por entender, entre otras cosas, que estamos rompiendo el pacto intergeneracional que constituye la esencia de nuestro sistema de pensiones. Una vez más, el Proyecto propiciara la precipitación de jubilaciones, como ya lo hicieron las reformas precedentes, y fomentara un efecto "huida". Deterioro que se une a la disminución de ingresos, propiciada por la destrucción de empleo y la reducción generalizada de salarios.

Finalizado el trámite parlamentario, con algunas variaciones que apuntaré más adelante, el proyecto se convirtió en la Ley 23/2013, de 23 de diciembre, publicada en el Boletin Oficial del Estado el 26 de diciembre, entrando en vigor al dia siguiente de su publicación, a excepción del factor de sostenibilidad que se aplicara a las pensiones de jubilación del Sistema de la Seguridad Social que se causen a partir del 1 de enero de 2019 (Disp. Final $5^{\mathrm{a}}$ ). ${ }^{505}$

La Ley sigue en lo fundamental las consideraciones del Informe de los Expertos, y diseña un Factor de sostenibilidad vinculado a la esperanza de vida (en el Informe denominado Factor de Equidad Intergeneracional.FEI), que se tendrá en

504 Puede consultarse : http://www1.seg-social.es/ActivaInternet/groups/public/documents/ rev_anexo/rev_032187.pdf

505 Un análisis de la Ley en TORTUERO PLAZA,JL. Ley 23/2013, de 23 de diciembre, reguladora del factor de sostenibilidad y del índice de revalorización del sistema de pensiones de la Seguridad Social: régimen jurídico, Rev. Relaciones Laborales núm. Monográfico dedicado a la reforma de las pensiones, 2014, págs.. 109-130. 
cuenta en el cálculo de la pensión de jubilación, una vez aplicada la formula general. Igualmente, fija un denominado Índice de revalorización de las pensiones (en el Informe denominado, Factor de Revalorización Anual, FRA) que rompe con la tradicional vinculación al IPC, fijando un porcentaje "suelo" y "techo", de forma que la revalorización de las pensiones se mueva en un margen determinado.

Por lo que refiere al Factor de Sostenibilidad, se aplicará, en los términos establecidos en esta ley, por una sola vez para la determinación del importe inicial de las nuevas pensiones de jubilación del sistema de la Seguridad Social, para lo cual se modifica el apartado 1 del artículo 163 de la LGS. Esto quiere decir que su impacto alcanza exclusivamente a los trabajadores por cuenta propia, ajena y asimilados incorporados a la LGS, por tanto, no es aplicable a Clases Pasivas del Estado y al resto de las pensiones con cargo a fondos públicos

Por el contrario, el Índice de Revalorización será aplicable tanto a los incorporados a la LGSS, como a Clases Pasivas del Estado, para lo cual se modifican las normas reguladoras para los referidos colectivos, esto es, el apartado 1 del artículo 27 del texto refundido de la Ley de Clases Pasivas del Estado, aprobado por el Real Decreto Legislativo 670/1987, de 30 de abril y el artículo 48 del texto refundido de la Ley General de la Seguridad Social, aprobado por el Real Decreto Legislativo 1/1994, de 20 de junio.

En ambos preceptos, la revalorización de las pensiones (a partir del 1/I/2014) se vincula "al índice de revalorización previsto en la correspondiente Ley de Presupuestos Generales del Estado".

Por lo que refiere a la determinación del "suelo "y el "techo" aplicable a la revalorización anual de las pensiones, se establece que "en ningún caso el resultado obtenido podrá dar lugar a un incremento anual de las pensiones inferior al 0,25 por ciento ni superior a la variación porcentual del Índice de Precios al Consumo en el periodo anual anterior a diciembre del año t, más 0,50 por ciento". En el Proyecto de Ley, el techo se incrementaba en el 0,25.

En efecto, en su aplicación, los arts. 37 y 41 de la LPGE 2014, establecen que "Las pensiones contributivas de Seguridad Social, así como las de Clases Pasivas del Estado, experimentarán en el año 2014 un incremento del 0,25\%, sin perjuicio de algunas excepciones...".

Los límites fijados significan, que las pensiones nunca se congelan en términos absolutos (si entendemos que subir 2 euros al mes, no constituye congelación), pero el poder adquisitivo perdido, tampoco se recupera, pues lo impide el límite o "techo" de revalorización fijado para los años de bonanza económica.

\subsubsection{La reforma y la ruptura del consenso político y social}

No debemos olvidar que la Ley 27/2011 constituyó el fruto de un gran consenso entre las fuerzas políticas (a través de la Comisión del Pacto de Toledo) 
y de las organizaciones sociales, a través del Pacto Social que sustenta la reforma.

Recuérdese, basta con hacer algo de historia, que el consenso referido no ha sido fácil de alcanzar, buena prueba de ello es el análisis de las principales reformas realizadas desde el año 1997, donde el consenso nunca fue global.

Sin perjuicio de la decisión legítima tomada por el Gobierno de nombrar un Comité de Expertos, lo cierto es que la decisión no ha sido consensuada ni en el marco del Pacto de Toledo, ni con los interlocutores sociales, lo que anunciaba una posición "poco receptiva" al informe del Comité, como asé fue. A ello, debemos añadir el impacto social de las medidas, que sin duda tendrán su respuesta social, tanto por las medidas en sí mismas de gran sensibilidad social, como por el efecto acumulativo respecto de otras medidas tomadas. En definitiva, la ruptura del consenso constituira una provocación innecesaria e injustificada.

Por último y a pesar de la importantísima problemática existente, no debemos olvidar que el sistema español cuenta con un Fondo de Reserva para equilibrar en el corto plazo los efectos negativos del ciclo y que las cohortes del baby boom (1957-1977) anuncian su llegada, pero en un plazo (2022-2042) que nos permite actuar con un margen razonable, alejado de la urgencia inmediata. Ésta es una de las diferencias con nuestro socios europeos donde sus generaciones del baby boom (1946-1964) ya comenzaron su llegada a la jubilación a partir del 2011 (si tomamos la edad de 65 años, no compartida en todos los Estados), de ahí que las reformas y ajustes de sus sistemas se realizaran en un tiempo anterior.

\section{LA FUNCIÓN DE LAS PRESTACIONES TEMPORALES: LA INCAPACIDAD TEMPORAL}

Los sistemas de protección social incorporan mecanismos de protección de carácter temporal, que tienen como función cubrir las vicisitudes que se producen durante la vida laboral. Dependiendo de cada sistema o modelo el abanico prestacional cubre la incapacidad temporal, la maternidad y los riesgo a ella vinculados, la paternidad y el desempleo. Si bien cada situación tiene su propia configuración, justificación y ordenación, un elemento común es la naturaleza temporal del estado de necesidad que cubren.

Del conjunto prestacional descrito, nos ocuparemos singularmente de la incapacidad temporal para el trabajo.

La incapacidad temporal es una situación de incapacidad para trabajar causada por accidente o enfermedad, que requiere asistencia y que se supone transitoria o de corta duración. Es una de las contingencias que concede a tal efecto dos tipos de prestaciones: una prestación en especie, en forma de asistencia sanitaria, y una prestación económica, que lógicamente tiene la finalidad de sustituir la pérdida de los ingresos propios del trabajo durante ese período. La situación que en este caso protege la seguridad social no es sólo la alteración de la salud, sino también la pérdida temporal de ingresos (del salario, si se trata de trabajador asalariado) que como 
consecuencia de la misma puede sufrir quien vive de su trabajo.

La contingencia de incapacidad temporal puede surgir de riesgos profesionales o de riesgos comunes, esto es, de accidente de trabajo o accidente no laboral, y de enfermedad profesional o enfermedad común. En el fondo de todo ello existe un proceso patológico de intensidad suficiente como para imposibilitar la realización del trabajo por lo que inevitablemente requiere una decisión no sólo de carácter administrativo o burocrático, sino también de carácter médico, lo cual plantea un problema básico en la determinación y calificación de esta contingencia: la necesaria concurrencia de criterios técnico-administrativos (que residen en las instituciones de seguridad social) y criterios médicos (que pertenecen a las instituciones sanitarias).

\section{EL MODELO DE GESTIÓN Y CONTROL DE LA INCAPACIDAD TEMPORAL: UN PRO- CESO DE REFORMA INTERMINABLE}

En un largo proceso de reformas que ya dura más de veinte años - desde 1992- la incapacidad temporal ha sido el centro de atención del legislador- y de la doctrina científica ${ }^{506}$ - realizando reformas continuas -y no siempre debidamente

506 Una incompleta pero grafica reseña de la preocupación doctrinal por la materia es la siguiente: AA.VV.: La incapacidad temporal (Coord. OJEDA AVILES, A.), Tecnos, Madrid, 1996; AA. VV.: Cuestiones en torno a la Incapacidad Temporal (Dir. SEMPERE NAVARRO, A. V.), Cinca, Madrid, 2011; ALONSO OLEA, M. y TORTUERO PLAZA, J. L., Instituciones de Seguridad Social, Civitas, 18 edic., Madrid, 2006; ALVAREZ DE LA ROSA. M. Incapacidad temporal y maternidad, en "Tribuna Social" n 53; ARETA MARTÍNEZ, M"., "La incapacidad temporal de los funcionarios públicos", AA. VV.: Cuestiones en torno a la incapacidad temporal de los funcionarios públicos, Cinca, Madrid, 2011; BARBA MORA, A., Incapacidad temporal, Tirant Lo Blanch, Valencia, 2000; BLÁZQUEZ AGUDO, E. Mª., "Presente y futuro de las mutuas de accidentes de trabajo y enfermedad profesional", Aranzadi Social Revista Doctrinal, núm. 2, 2012; BRUNA REVERTER, J., La incapacidad laboral: problemática legal, jurisprudencial y médica, Comares, Granada, 2012; CARRIZOSA PRIETO, E., "La tutela del trabajador enfermo en el Estatuto de los Trabajadores", Revista Española de Derecho del Trabajo, núm. 157, 2013; CASTILLA CASTILLA, Á., "Control médico de la Incapacidad Temporal: la reordenación de las competencias de las entidades que intervienen en la prestación de la Incapacidad Temporal: artículo 128 de la LGSS", Revista de Información Laboral, núm. 3, 2012; CASTRO CONTE, M., "Evolución de la Seguridad Social de los trabajadores autónomos o por cuenta propia", AA. VV.: Cuestiones en torno a la Incapacidad Temporal (Dir. SEMPERE NAVARRO, A. V.), Cinca, Madrid, 2011; DESDENTADO BONETE, A. y TEJERINA ALONSO, J. I. El subsidio de la incapacidad temporal. Cuantía, nacimiento, duración y extinción en "Tribuna Social", núm. 44-45, 1.994; DESDENTADO BONETE, A “Mutuas de accidentes de trabajo y Seguridad Social: puntos críticos desde la perspectiva de la gestión de la incapacidad temporal". Actualidad Laboral. No 6. 2008; DUEÑAS HERRERO, L. F., "La contingencia de incapacidad (laboral) temporal en el régimen general de Seguridad Social”, Relaciones Laborales, núm. 4, 1996; FERNANDEZ LOMANA GARCÍA, M., «El control por las Mutuas de Accidentes de Trabajo de las 
bajas médicas por contingencias comunes: situación actual y perspectiva», Actualidad Laboral nº 8, 2008;FERNANDEZ ORRICO, F J “Medidas encaminadas a racionalizar el subsidio de incapacidad temporal por Ley30/2005, de 29 de diciembre, AA VV "La economía de la Seguridad Socia. Sostenibilidad y viabilidad del sistema”. Laborum. 2006; FERNÁNDEZ PRATS, C., La protección de la incapacidad temporal en el régimen general de la Seguridad Social, Tirant lo Blanch, Valencia, 2011; GARCÍA MURCIA J. y ROMÁN VACA, E., "Nuevas pautas de la regulación de la incapacidad temporal", Aranzadi Social, núm. 2, 1996; GARCÍA NINET, J. I., "La incapacidad temporal", AA.VV.: La incapacidad temporal, (Coord. OJEDA AVILES, A.), Tecnos, Madrid, 1996; GARCÍA QUIÑONES, J. C., “Ampliación de la prestación por incapacidad temporal para los trabajadores por cuenta propia”, Documentación Laboral, núm. 70, 2004; GARCÍA VIÑA, J. El deber recíproco de buena fe en la incapacidad temporal, en AA.VV.(COOR. A. OJEDA AVILES), La incapacidad temporal, 1996 ; GIL PLANA, J y GONZALEZ DEL RIO, J M “Aspectos polémicos en la colaboración de las Mutuas en la gestión de la Seguridad Social”. Revista Española de Derecho del Trabajo GOERLICH PESET, J M "La reforma de la incapacidad temporal” en VV.AA "La reforma de la Seguridad Social”. Ed. Tirant lo Blanch. 2008; GONZÁLEZ ORTEGA, S., "El control de las bajas médicas como objetivo permanente de las reformas de la incapacidad temporal (I) (El control durante la primera fase de la incapacidad temporal, Relaciones Laborales, núm. 12, 2011; "Prórrogas y recaídas. El tránsito hacia la incapacidad permanente", Relaciones Laborales, núm. 13, 2011 ; GRANADO MARTINEZ, O "El control de la incapacidad temporal en el Instituto Nacional de la Seguridad Social en AA VV "La economía de la Seguridad Social. Sostenibilidad y viabilidad del sistema”. Laborum. 2006I); JOVER RAMÍREZ, C., La incapacidad temporal para el trabajo. Aspectos laborales y de seguridad social, Tirant lo Blanch, Valencia, 2006; LÓPEZ INSUA, B. M., La incapacidad temporal en el Sistema de la Seguridad Social, Comares, Granada, 2014; MARTÍN VALVERDE, A., "Incapacidad laboral transitoria e Invalidez Provisional: legislación y jurisprudencia", Actualidad Laboral, núm. 39, 1994; MARTINEZ-GIJON MACHUCA, M A "Sobre la incapacidad laboral: tránsito entre prestaciones y duración de la temporal (al hilo de la reforma operada por la Ley 30/2005). Relaciones Laborales. N²1. 2006; MARTINEZ-GIJON MACHUCA, M A "Sobre la incapacidad laboral: tránsito entre prestaciones y duración de la temporal (al hilo de la reforma operada por la Ley 30/2005). Relaciones Laborales. No 21. 2006; MERCADER UGUIA, JR., El control de la incapacidad temporal (historia de una sospecha), en Revista de Relaciones Laborales, Tomo I/2004; MONEREO PEREZ, JL y FERNANDEZ AVILES, JA. Determinación de la contingencia, en AAVV (Dir. BORRAJO DACRUZ) Accidentes de Trabajo y Mutuas, edit. Lay y Fremap, Madrid, 2009; MONERO ROMERO, F "La responsabilidad empresarial en materia de prestaciones a la luz de la incapacidad temporal". AA.VV, "La responsabilidad del empresario". Ediciones Laborum. 2012. y "El papel de las mutuas en la gestión de la incapacidad temporal: Previsiones sobre la nueva ordenación". en AAVV, Público y Privado en el Sistema de Seguridad Social. AESSS. Ediciones Laborum, Murcia, 2013; MUÑOZ MOLINA, J., La incapacidad temporal como contingencia protegida por la Seguridad Social, Aranzadi, Pamplona, 2005; OLARTE ENCABO, S., "Control y gestión de la incapacidad temporal: análisis crítico del marco jurídico-positivo vigente, el complejo equilibrio entre eficiencia y garantismo", Aranzadi Social Revista Doctrinal, núm. 20, 2011; 2006; PANIZO ROBLES, J El control de la incapacidad temporal: A 
propósito del Real Decreto 575/11997, de 18 de abril”. Revista del Ministerio de Trabajo y Asuntos Sociales. No 4/ 1997; "De nuevo sobre el control de la IT (A propósito del Real Decreto 1117/1998)”. En Revista de Trabajo y Seguridad Social. CEF. No 187. Septiembre.1998; "La Seguridad Social en los comienzos de 2006 (comentario a las novedades incorporadas a la Ley 30/2005, de 29 de diciembre, de Presupuestos Generales del Estado para 2006 y en otras disposiciones legales y reglamentarias de reciente promulgación).” Revista de Trabajo y Seguridad Social. CEF. No 275. Enero 2006; , "Un nuevo paso en el control de la prestación de la seguridad social por incapacidad temporal: el RD 1430/2009, de 4 de diciembre", Revista de Trabajo y Seguridad Social, CEF, núm. 320, 2009; PÉREZ ALONSO, M. A., La incapacidad temporal, Tirant lo Blanch, Valencia, 1995; PUEBLA PINILLA, A “El alta médica: efectos laborales e impugnación por el trabajador. Examen especial de la posición de las Mutuas de accidentes de trabajo". Actualidad Laboral. N 11. Junio 2008; PURCALLA BONILLA, M. A., "Incapacidad temporal y control del absentismo", AA. VV.: Régimen jurídico y gestión racional del tiempo en la empresa (Dirs. ROMERO BURILLO, A. M ${ }^{\mathrm{a}}$ y ARGÜELLES BLANCO, A. R.), Aranzadi, Cizur Menor, 2013; RIOS SALMERON, B y FERRANDO GARCIA, F “La prestación por incapacidad temporal: equilibrio entre la protección y control del fraude” FORO DE SEGURIDAD SOCIAL. Mayo 2007; RODRÍGUEZ ÁLVAREZ, V., "Evolución de la normativa sobre la incapacidad para el trabajo en el ordenamiento jurídico español", Revista del Ministerio de Trabajo e Inmigración, núm. 94, 2011; RODRÍGUEZ ESCANCIANO, S., "El control de la incapacidad temporal: su incidencia sobre la contención del gasto público y el aumento de la productividad empresarial", Temas Laborales, núm. 118, 2013; SALA FRANCO, T., La incapacidad temporal para trabajar derivada de enfermedad o accidente, Tirant Lo Blanch, Valencia, 2005; SALA FRANCO, T y SALAS BAENA, A “La incapacidad temporal: aspectos laborales, sanitarios y de Seguridad Social”. Ed. Tirant Lo Blanch. Valencia, 2007 SANTAMARIA RUIZ, M D “Gestión y control de la prestación económica por incapacidad temporal: una gestión compleja”. Foro de Seguridad Social. No 13-14, 2005; SIRVENT HERNANDEZ,N, "Nuevas medidas de control en la gestión de los procesos de incapacidad temporal introducidas a raíz de la Ley 35/2010, de 17 de septiembre", Actualidad Laboral núm. 16, 2011 ; TOROLLO GONZÁLEZ, F. "Las mutuas y su lugar de conflictos jurídicos derivados de la incapacidad temporal", en AAVV. Público y Privado en el Sistema de Seguridad Social. AESSS. Ediciones Laborum, Murcia, 2013; TORTUERO PLAZA, J.L. "la incapacidad temporal para el trabajo en la seguridad social", Madrid, Tesis Doctoral, 1.987; "La incapacidad temporal, contingencia y situaciones protegidas: un análisis teórico", Tribuna Social, núms. 44/45, 1994; "Régimen jurídico de la incapacidad temporal: una perspectiva general". Foro de Seguridad Social. No 12-13. 2005; "Apuntes sobre la reforma de la incapacidad temporal”. En AA VV. "La economía de la Seguridad Social. Sostenibilidad y viabilidad del sistema”. Laborum. 2006; "El control público de las Mutuas en materia de incapacidad temporal", AA. VV.: Accidentes de trabajo y Mutuas, La Ley, Madrid, 2008; TORTUERO PLAZA, J. L. y MORENO ROMERO, F., "Poder de dirección del empresario y los mecanismos de control de la incapacidad temporal: la opción por el control público", AA. VV.: Libertad de empresa y poder de dirección del empresario en las relaciones laborales: estudios ofrecidos al profesor Alfredo Montoya Melgar, Aranzadi, Cizur Menor, 2011; TORTUERO PLAZA,JL. Y MORENO ROMERO,F. La reforma de la Incapacidad Temporal en la Ley 35/2010 y materias conexas, en 
maduradas- con la finalidad de construir un nuevo modelo de gestión y control, que permita recomponer el papel que deben asumir las entidades intervinientes en el proceso, reconducir su utilización -no siempre ortodoxa- y situar el gasto en parámetros de racionalidad.

Cierto es que en la incapacidad temporal intervienen todo un conjunto de sujetos e instituciones - Servicio Público de Salud, Mutua de accidentes de trabajo y enfermedades profesionales, Instituto Nacional de la Seguridad Social, Instituto Social de la Marina, empresario y trabajador, así como, en ocasiones, al Servicio Público de Empleo Estatal- que dificultan su ordenación, singularmente desde la esfera competencial. No obstante y como veremos, el equilibrio, la ponderación y la racionalidad no se han conseguido, ¡después de más de 20 años de reformas!, ¿tan difícil es?

Cierto es también, que en su momento asistimos a un constante y alarmante incremento del gasto en incapacidad temporal, que justifico en parte que las principales reformas de los últimos años se hayan centrado casi en exclusividad sobre la ordenación de los mecanismos de control, bajo la hipótesis de que un mayor control conducirá a una reducción del gasto. No obstante, las reformas no se plantearon la problemática existente en forma sosegada y reflexiva, sino más bien conducidas por la obsesión razonable del gasto y la idea de que el fin justifica cualquier medio. En este orden, el aluvión normativo, producido entre el año 1997 y el año 2007, buscó la reordenación de los mecanismos de control con la finalidad de alcanzar el resultado económico deseado. No obstante, desde hace años el gasto en incapacidad temporal alcanzo el espacio normalidad y, aun más, la crisis económica se ha encargado de reducirlo considerablemente, tanto por razones técnicas - menos afiliados, menos salarios...-, como humanas, el miedo a perder el empleo ha hecho que el trabajador -salvo en situaciones extremas- acuda a trabajar estando incapacitado.

Por último, otra asignatura pendiente, es el frecuente desencuentro entre el contrato de trabajo y la incapacidad temporal. Como sabemos, a tenor de lo estable-

AA.VV (Dir. ANTONIO V. SEMPERE NAVARRO) "La reforma Laboral de 2010. Estudio de la Ley 35/2010, de 17 de septiembre, de Medidas Urgentes para la Reforma del Mercado de Trabajo" Editorial: Thomson Reuters. Aranzadi. Pamplona, 2010; TORTUERO PLAZA J. L. y SÁNCHEZ-URÁN AZAÑA, Y., "La incapacidad temporal. Régimen jurídico y negociación colectiva", Fundación MAPFRE, Madrid, 1996;TOSCANI GIMENÉZ, D., "La impugnación judicial de las altas médicas emitidas por las entidades gestoras de la seguridad social", Revista capital Humano, núm. 257/21011; Laborum. 2006; VALLE JOZ, J y TRILLO GARCIA, A "Las Mutuas de accidentes de trabajo y enfermedades profesionales como gestoras de la incapacidad temporal derivada de contingencias comunes". en VV.AA "Mutuas de accidentes de trabajo y enfermedades profesionales". La Ley, 2007; VALLE MUÑOZ A., "La facultad de control por las Mutuas Patronales de los procesos de incapacidad temporal mediante reconocimientos médicos, Aranzadi Social 22/2011; VICENTE PALACIO, M. A., "El control de la Incapacidad Temporal: el control en el ámbito de la relación laboral individual y en el ámbito de la Seguridad Social”, Tribuna Social, núm. 168, 2004. 
cido en el artículo 45. 1.c) del Estatuto de los Trabajadores, la incapacidad temporal es causa de suspensión del contrato de trabajo, quedando vinculado el espacio suspensivo a las reglas sobre nacimiento, duración y extinción de la incapacidad temporal establecidas en la normativa de la seguridad social, singularmente en la LGSS. Esto que parece elemental, no lo debe ser, ya que el legislador suele olvidarse con cierta frecuencia de los efectos que las normas de seguridad social tienen sobre el contrato de trabajo, olvido que adquiere especial relevancia, cuando la norma laboral delega tácitamente su ordenación en las de seguridad social, como es el caso de la incapacidad temporal.

\section{Nuevas Reglas de gestión y CONTROL: el Real Decreto 625/2014}

\subsection{UBICACIÓN Y ALCANCE DE LA REFORMA}

Después de un largo periodo en incubación y siempre al rebufo del denominado Proyecto de Ley de Mutuas, el Boletín Oficial del Estado publico el día 21 de julio, el Real Decreto 625/2014, de 18 de julio, por el que se regulan determinados aspectos de la gestión y control de los procesos por incapacidad temporal en los primeros trescientos sesenta y cinco días de su duración.

El RD 625/2014 viene a sustituir a su precedente, -que es derogado expresamente por la disposición derogatoria única- el Real Decreto 575/1997, de 18 de abril, por el que se regulan determinados aspectos de la gestión y control de la prestación económica de la Seguridad Social por incapacidad temporal.

Ciertamente el RD 575/1997, de 18 de abril, había quedado desfasado en muchos de sus contenidos, lo que es habitual en materia de seguridad social, donde rara vez la reforma de la LGSS va acompañada del correspondiente texto reglamentario, bien para sustituir al viejo ,bien para adaptarle.

Como indica el titulo del RD -regulación de "determinados aspectos..."no se pretende proceder a dar una regulación completa, unitaria y acabada de la gestión y control de la incapacidad temporal, sino abordar aspectos parciales, de suma importancia, pero parciales. Nuevamente y una vez más, perdemos la oportunidad de proceder -después de un largo periodo de gestación de la norma- a abordar una regulación completa, optando de forma incomprensible por la ordenación parcelada. La parcelación, provoca ausencia de globalidad y por tanto de visión y ordenación de conjunto, más aun cuando las normas reguladoras tienen infinidad de conexiones.

Las materias objeto de reforma son múltiples y de distinto alcance. A modo de resumen afectan a las siguientes materias:

$>\quad$ La nueva ordenación es aplicable a los primeros 365 día, cualquiera que sea la contingencia determinante - accidente de trabajo, enfermedad profesional, enfermedad común y accidente no laboral- y cualquiera que sea el régimen - general o especiales-, reflejando su vocación universal. 
$>\quad$ Deja fuera como suele ser habitual a los denominados los regímenes especiales de las Fuerzas Armadas, de los Funcionarios Civiles de la Administración del Estado y del personal al servicio de la Administración de Justicia.

D Se moderniza la gestión formal (partes de baja, confirmación y alta) diferenciando los procesos según su duración estimada - inferior a cinco día, entre 5 y 30 días naturales; entre 31 y 60 y entre 61 y más días- en base a protocolos técnico-sanitarios, con identificación de los sujetos responsables en función de la contingencia y de los contenidos de los nuevos partes. $>\quad$ Se apuesta por la gestión telemática en todas las fases y respecto de todos los intervinientes.

$>\quad$ Se reconoce y facilita el acceso a la información clínica del trabajador incapacitado en una ordenación extendida a "los trabajadores del sistema de seguridad social.

$>\quad$ Ordena el procedimiento para las propuestas de alta médica formuladas por las mutuas en los procesos derivados de contingencias comunes. $>\quad$ Ordena en desarrollo del artículo 132.2 de la LGSS los requerimientos para reconocimientos médicos de control y la suspensión cautelar de la prestación ante la falta de comparecencia del trabajador.

> Incorpora un nuevo artículo 6 al RD 1430/2009, donde se regula el procedimiento administrativo de determinación de la contingencia causante en los procesos de incapacidad temporal.

$>\quad$ Igualmente, incorpora un nuevo artículo 7 al RD 1430/2009, donde se regula la prolongación de efectos de la incapacidad temporal y agotamiento de la misma.

\subsection{Elementos DESTACABLES DE LA REFORMA Y SUS PUNTOS CRÍTICOS}

\subsubsection{Instrumentos de control sobre la actuación de los facultativos y centra-} lización de la información

La nueva ordenación realizada por el RD 625/2014 de los elementos formales vinculados al nacimiento, duración y extinción de la incapacidad temporal - baja médica, confirmación y alta-, son estructurados de forma que en sí mismos constituyen mecanismos de control que pretenden actuar contra la utilización inadecuada de la contingencia, tanto en lo que refiere a su nacimiento, como en su duración. Los instrumentos son múltiples - imposición de protocolos clínicos, fragmentación temporal de los procesos, códigos de diagnostico, código nacional de ocupación, informes complementarios...- y pretenden controlar la acción médica y centralizar la información, cualquiera que sea la entidad gestora, a través de medios telemáticos en el Instituto Nacional de la Seguridad Social. 


\subsubsection{La fragmentación temporal de los procesos como mecanismo control -presión}

Otro de los mecanismos de control novedosos se centra en la fragmentación de los procesos de incapacidad en función de su posible duración (inferior a cinco días naturales, entre 5 y 30 días, entre 31 y 60 días y de 61 o más días), lógicamente según los protocolos aplicables. A pesar del revestimiento de buenas intenciones y justificaciones tecnológicas contenidas en la Exposición de Motivo se hace patente expresamente -se cuela en el discurso- la clara intencionalidad del "control".

Es claro que tras la apariencia de facilitar la expedición y tramitación de los partes médicos, se ejercita y drástico mecanismo de control y de presión sobre el facultativo y sobre el trabajador, al predeterminarse la fecha de alta médica en cada proceso.

El elemento de presión-control consistente en la predeterminación temporal del parte de alta médica y, por tanto, de la extinción de la incapacidad temporal, tiene posiblemente un efecto adicional. Cuando el alta predeterminada no se consolide, bien por la modificación del diagnostico, bien por la evolución del propio proceso, actuará como señal de alarma para la actuación puntual de los inspectores médicos del Instituto Nacional de la Seguridad Social, en la medida en que tienen competencias para expedir el alta médica. Actuación que, como hemos visto, viene facilitada por la información recibida por el INSS desde el mismo momento en que se expide la baja médica, como por el acceso telemático a toda la información clínica del trabajador, como reiteradamente recoge el RD.

Ciertamente se respeta el derecho del trabajador, pero a través de un acto expreso, lo que evidentemente constituye un condicionante, sobre todo sí como presumimos, queda vinculado a la acción inspectora de los facultativos del INSS o en su caso del servicio público de salud. Actuación de unos y otros inspectores, que tiene como efecto adicional en caso de expedir el alta médica, la asunción de la competencia sobre el control futuro de la patología - con la correspondiente perdida de competencias del facultativo que trata al trabajador-, al establecerse que durante los ciento ochenta días naturales siguientes a la fecha en que se expidió el alta, serán estas entidades las únicas competentes, a través de sus propios médicos, para emitir una nueva baja médica por la misma o similar patología.

\subsubsection{Facultades de control y la posible vulneración del derecho a la intimi- dad}

La gestión sanitaria vinculada a la incapacidad temporal se moderniza, apostando por la utilización de procedimientos telemáticos, tanto en la gestión de los elementos formales - que se ordenan en función del previsible tiempo de baja - , en la utilización de protocolos, que pretenden dotar al facultativo de herramientas de 
respaldo técnico, y en el acceso a la documentación clínica del trabajador por parte de las instituciones con competencias en materia de gestión y control. Parece que la apuesta por los protocolos es excesiva, olvidándose que más que enfermedades existen enfermas.

En este orden y con insuficiente rango legal, el artículo 8 del RD, incorpora una competencia abusiva, a saber, que "los inspectores médicos del Instituto Nacional de la Seguridad Social o, en su caso, del Instituto Social de la Marina, para el ejercicio de sus competencias, tendrán acceso, preferentemente por vía telemática, a la documentación clínica de atención primaria y especializada de los trabajadores del sistema de la Seguridad Social". La carencia de rango legal y el carácter abusivo de la competencia no se soluciona con la coletilla habitual que advierte que "el tratamiento de los datos de los trabajadores afectados así como el acceso a los mismos quedará sujeto a lo dispuesto en la Ley Orgánica 15/1999, de 13 de diciembre, de Protección de Datos de Carácter Personal y en sus disposiciones de desarrollo" (art.8.3). Repárese en que los apartados 1 y 2 del artículo 2 de la Ley Orgánica 1/1982, de 5 de mayo, sobre protección civil del derecho al honor, a la intimidad personal y familiar y a la propia imagen, dictada en desarrollo del artículo $18.1 \mathrm{CE}$, establecen que " la protección civil de la intimidad y de la propia imagen quedará delimitada por las leyes...", " no se apreciará la existencia de intromisión ilegítima en el ámbito protegido cuando estuviere expresamente autorizada por Ley ...”. El RD busca apoyo en la disposición adicional cuadragésima de la LGSS, sin embargo, ésta refiere a “...datos médicos estrictamente relacionados con las lesiones y dolencias padecidas por el interesado que resulten relevantes para la resolución del procedimiento...". El diferente ámbito es notable y, por tanto, la autorización legal resulta insuficiente. 